\title{
Electrical stimulation of the motor tracts in cervical spondylosis
}

\author{
G A B B R UZZESE, D DA L L'A GATA, M MORENA, S S I MONETTI, \\ L SPADAVECCHIA, † P SEVERI, * GCANDRIOLI, * E FAVALE
}

From the Department of Neurology, University of Genoa, Department of Neurosurgery, ${ }^{*}$ Galliera Hospital, Genoa, and Institute of Cybernetics and Biophysics, $\dagger$ C.N.R., Genoa, Italy

SUMMARY Motor action potentials evoked by percutaneous electrical stimulation of the scalp and of the cervical (or lumbar) vertebral region were recorded from the biceps, thenar and tibialis anterior muscles in 30 patients with cervical spondylosis. Twelve normal controls were matched for age and height. Abnormalities of central motor conduction (absence or increased central delay of cortical responses) for at least one muscle were observed in all (but one) the patients with myelopathy alone or combined with radiculopathy. An increase in latency of the responses evoked by cervical stimulation occurred in $40 \%$ of patients with radiculopathy or myelo-radiculopathy. Changes of motor conduction occurred even in the absence of abnormalities of somatosensory evoked potentials, while the opposite was never observed. Direct stimulation of the motor tracts may be of value in the functional assessment of the motor pathways in cervical spondylosis.

The neurological manifestations of cervical spondylosis reflect the anatomical damage of central (spinal cord) and peripheral (segmental roots) nervous structures. The functional involvement of sensory pathways can be assessed by the somatosensory evoked potentials. ${ }^{1}$ An equivalent investigation of the motor pathways, whose involvement is responsible for many of the major neurological signs in cervical spondylosis, ${ }^{23}$ would be desirable.

Percutaneous electrical stimulation of the motor cortex ${ }^{4}$ has been proved useful in assessing the functional integrity of central motor pathways in patients with various neurological disorders. ${ }^{6-11}$ Similarly, defects in the conduction of motor impulses through the proximal segments of the peripheral pathways can be documented by percutaneous stimulation of the cervical or lumbar vertebral regions.

In this study the diagnostic relevance of direct cortical and spinal stimulation has been evaluated in a group of patients with sensorimotor deficits due to cervical spondylosis, also with respect to conventional electrophysiological techniques.

Address for reprint requests: Prof Emilio Favale, Clinica Neurologica Universita', Via De Toni 5, I-16132 Genova, Italy.

Received 30 October 1987 and in revised form 12 January 1988. Accepted 21 January 1988

\section{Patients and methods}

Thirty patients (21 males and nine females, aged 37-73 years, mean 56.0 , SD 10.4 years) with symptomatic evidence of cervical spondylosis were studied. Patients presented clinical signs of: (a) posterior column involvementec (impairment of joint position and vibration sense), and/or? (b) antero-lateral column involvement (upper motor neuron signs, disturbance of bladder control, impairment of pain and temperature sensation), and/or (c) radicular involvement (weakness and wasting in the upper limbs, diminished tendon reflexes). The diagnosis was confirmed in all cases by plain radiographs of the cervical spine and by at least one of the following investigations: myelography ( 22 cases), computed tomography (10 cases), nuclear magnetic resonance imaging ( 9 cases). Relevant laboratory investigations, including complete CSF analysis, were performed to exclude other causes of cervical cord and/or root disease.

The patients were classified into three groups according to the clinical features: (1) Myelopathy alone (12 cases): 7 males and 5 females, mean age 56.8, SD 9.1 years, mean height 164.8 , SD $6.9 \mathrm{~cm},(2)$ Combined myelopathy and radiculopathy ( 12 cases): 10 males and 2 females, mean age 58.6 SD 11.9 years, mean height 170.4 , SD $8.3 \mathrm{~cm}$, (3) Radiculopathy alone ( 6 cases): 4 males and 2 females, mean age $49 \cdot 3$, SD $7 \cdot 8$ years, mean height $166 \cdot 3$, SD $7 \cdot 4 \mathrm{~cm}$.

The results obtained in patients were compared with those of 12 control subjects matched by age and height $(10$ males and 2 females, aged 27-68 years, mean 52.5, SD 14.0, mean height $170 \cdot 4$, SD $9.6 \mathrm{~cm}$ ). Informed consent was obtained from all the subjects and the study was approved by the local ethical committee. 


\section{Electrophysiological methods}

To stimulate the motor cortex and the cervical (or lumbar) region, a Digitimer D180 stimulator, delivering single electric shocks of up to $750 \mathrm{~V}$ with a time constant of $50-100 \mu \mathrm{s}$, was used. Stimulating electrodes were $\mathrm{Ag} / \mathrm{AgCl}$ cups $(1 \mathrm{~cm}$ diameter) fixed to the scalp by collodion. To activate arm muscles, the cathode was placed at the vertex and the anode $7 \mathrm{~cm}$ laterally on the line between the vertex and the external auditory meatus; when activating leg muscles, the anode was placed at the vertex and the cathode $6 \mathrm{~cm}$ anterior to it. Cervical and lumbar electrodes were placed respectively over the processes of $\mathrm{C} 4-\mathrm{T} 1$ and $\mathrm{D} 12-\mathrm{L} 4$, the anode being proximal to the cathode.

Muscle action potentials (MAPs) were recorded by surface electrodes placed on the biceps, thenar and tibialis anterior muscles. The EMG signals were amplified $(53 \mathrm{~Hz}-3 \mathrm{kHz},-3 \mathrm{~dB})$, displayed on a screen and stored on a floppy disk of an AIM 65 Rockwell computer for later analysis.

Single MAPs evoked by cortical stimulation were recorded while the subjects exerted a slight background con-

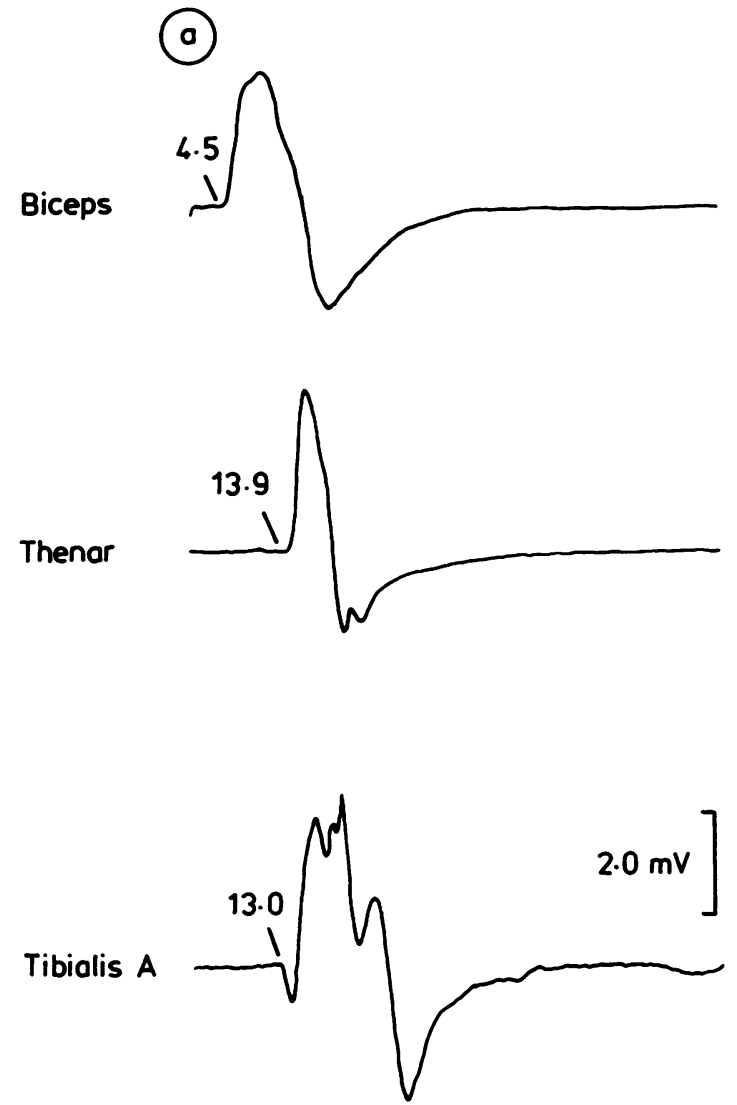

traction of the muscle from which the response was to be recorded, thus facilitating the shortest-latency EMG responses. ${ }^{512}$ Single MAPs evoked by cervical (or lumbar) stimulation, which are not influenced by voluntary muscle contraction $^{513}$ were collected while the subjects were relaxed. The stimulus intensity producing the shortest latency responses was adopted.

Onset-latency, duration and peak-to-peak amplitude of the compound MAPs were measured by the computer using a programme devised by Dr L Spadavecchia. Central motor conduction times (CCT) to the spinal segments innervating arm or leg muscles were calculated by subtracting the latency after cervical (or lumbar) stimulation from the latency after cortical stimulation. The absence of the response (at maximum stimulation intensity) or the occurrence of MAP latency and/or CCT values exceeding the upper confidence limit (mean + 3SD) of control population were adopted as abnormality criteria. The results were statistically analysed by ANOVA.

Conventional EMG recordings from upper limb muscles were performed with concentric needle electrodes. Motor
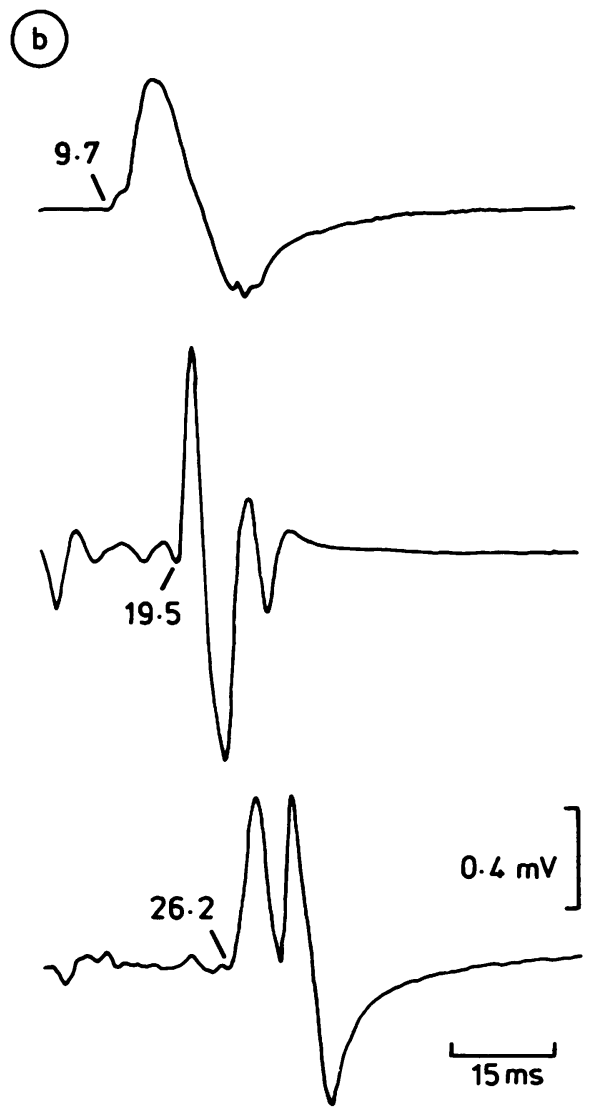

Fig 1 Motor action potentials (MAPs) evoked in the biceps, thenar and tibialis anterior muscles of a normal subject by spinal (a) and cortical (b) electrical stimulation. Background muscle contraction, during cortical stimulation, is evident in the second and third traces. In this and in the following figures, MAPs are illustrated as unsmoothed traces drawn by the computer. 
conduction velocity (MCV) of the median nerve was assessed bilaterally by stimulating the nerve at the elbow and wrist and recording from the opponens pollicis muscle. Fwaves were recorded from the same muscle upon $20 \%$ supramaximal stimulation of the median nerve at the wrist and the shortest latency determined.

Somatosensory evoked potentials (SEPs) were recorded after median nerve stimulation at the wrist from a cervical (between the second and the third cervical spines) and a parietal $(3 \mathrm{~cm}$ behind the vertex and $7 \mathrm{~cm}$ from the midline) electrode with a midfrontal reference. Cortical SEPs to stimulation of the posterior tibial nerve at the ankle were recorded (in groups 1 and 2) from an active electrode placed $2 \mathrm{~cm}$ behind the vertex on the midline with a midfrontal reference. Stimuli were $0.2 \mathrm{~ms}$ square waves delivered with a frequency of $1 \mathrm{~Hz}$ and an intensity just above motor threshold. At least three series of 256 responses were averaged over 50-100 ms by an AIM 65 Rockwell computer (bandpass: $16-3000 \mathrm{~Hz}$; sampling rate $10 \mathrm{kHz}$ per channel) with automatic rejection of samples with excessive EMG interference. The following latencies were considered: (a) the main negative peak of the cervical response (N13), (b) the main negative peak of the cortical response to median nerve stimulation (N20), (c) the main positive peak of the cortical response to tibial nerve stimulation (P40). Latency values were covariated for the height of the subjects. ${ }^{14}$ The normative data of the laboratory for median nerve MCV, F-wave and SEP latency were adopted and the upper confidence limit was established as mean +3 SD of normal population.

\section{Results}

\section{Controls}

In normal controls stimulation of the motor cortex

Table 1 Latency and central conduction times of motor responses evoked by direct cortical and spinal stimulation

\begin{tabular}{|c|c|c|c|c|}
\hline & Controls & Myelopathy & $\begin{array}{l}\text { Myelopathy + } \\
\text { radiculopathy }\end{array}$ & $\begin{array}{l}\text { ANOVA } \\
(F)\end{array}$ \\
\hline $\begin{array}{l}\text { Biceps } \\
\text { Cortical St. }\end{array}$ & $\begin{array}{l}n=12 \\
9 \cdot 85, \text { SD } 0 \cdot 44 \\
(9 \cdot 28-10 \cdot 64)\end{array}$ & $\begin{array}{l}\mathrm{n}=12 \\
10 \cdot 63, \mathrm{SD} 1.29 \ddagger \\
(9 \cdot 0-13.12)\end{array}$ & $\begin{array}{l}n=12 \\
11.41, S D 1 \cdot 56^{*} \\
(9 \cdot 6-15 \cdot 68)\end{array}$ & $10 \cdot 15^{*}$ \\
\hline Spinal St. & & $\begin{array}{l}5 \cdot 13, \text { SD } 0 \cdot 39 \\
(4 \cdot 48-5 \cdot 76)\end{array}$ & $\begin{array}{l}5.48, \text { SD } 0.45 \dagger \\
(4.48-6.4)\end{array}$ & $6.99 t$ \\
\hline $\mathrm{CCT}$ & $\begin{array}{l}4 \cdot 77, \text { SD } 0.33 \\
(4 \cdot 16-5 \cdot 17)\end{array}$ & $\begin{array}{l}5 \cdot 50, \text { SD 1.11† } \\
(4 \cdot 48-7 \cdot 72)\end{array}$ & $\begin{array}{l}5 \cdot 93, \text { SD } 1.38^{*} \\
(4 \cdot 80-9 \cdot 42)\end{array}$ & $7 \cdot 61+$ \\
\hline $\begin{array}{l}\text { Thenar } \\
\text { Cortical St. }\end{array}$ & $\begin{array}{l}n=12 \\
19 \cdot 19, \text { SD } 0.69 \\
(17 \cdot 94-20 \cdot 06)\end{array}$ & $\begin{array}{l}\mathrm{n}=12 \\
21 \cdot 38, \mathrm{SD} 2 \cdot 00^{*} \\
(18 \cdot 88-26 \cdot 56)\end{array}$ & $\begin{array}{l}\mathrm{n}=12 \\
24 \cdot 36, \mathrm{SD} 2 \cdot 66^{*} \\
(20 \cdot 80-29 \cdot 79)\end{array}$ & 9 \\
\hline Spinal St. & $\begin{array}{l}13.89, \text { SD } 0.74 \\
(12.77-15.04)\end{array}$ & $\begin{array}{l}13.55, \text { SD } 1.06 \\
(12.00-15.78)\end{array}$ & $\begin{array}{l}15.26, \text { SD } 0.88^{*} \\
(13.44-16.96)\end{array}$ & $24.05^{*}$ \\
\hline $\mathrm{CCT}$ & $\begin{array}{l}5 \cdot 30, \text { SD } 0 \cdot 30 \\
(4 \cdot 48-5 \cdot 76)\end{array}$ & $\begin{array}{l}7.83, \text { SD } 1.88^{*} \\
(5 \cdot 76-12 \cdot 80)\end{array}$ & $\begin{array}{l}9 \cdot 10, \text { SD } 2 \cdot 35^{*} \\
(5 \cdot 44-14 \cdot 39)\end{array}$ & $30 \cdot 73^{*}$ \\
\hline $\begin{array}{l}\text { Tibialis } A \text {. } \\
\text { Cortical St. }\end{array}$ & $\begin{array}{l}n=11 \\
26 \cdot 16, S_{1} 1.47 \\
(24 \cdot 58-28 \cdot 67)\end{array}$ & $\begin{array}{l}\mathrm{n}=11 \\
32 \cdot 69, \mathrm{SD} 3 \cdot 17^{*} \\
(27 \cdot 52-38 \cdot 40)\end{array}$ & $\begin{array}{l}n=9 \\
33 \cdot 56, \text { SD } 4 \cdot 41^{*} \\
(28 \cdot 42-41 \cdot 86)\end{array}$ & 32.9 \\
\hline Spinal St. & $\begin{array}{l}13.57, \text { SD } 1 \cdot 11 \\
(11.92-15 \cdot 32)\end{array}$ & $\begin{array}{l}13.92, \text { SD } 1.32 \\
(12 \cdot 3-16 \cdot 5)\end{array}$ & $\begin{array}{l}14.37, \text { SD } 0.55 \\
(13.44-14.98)\end{array}$ & $2 \cdot 13$ \\
\hline CCT & $\begin{array}{l}12.59, \text { SD } 0.74 \\
(11.37-14.28)\end{array}$ & $\begin{array}{l}18 \cdot 77, \text { SD } 3.65^{*} \\
(13 \cdot 12-24 \cdot 58)\end{array}$ & $\begin{array}{l}19 \cdot 19, \text { SD 3.76 } \\
(15 \cdot 08-26 \cdot 29)\end{array}$ & 37.9 \\
\hline
\end{tabular}

Mean, 1 SD(ms) ANOVA: ${ }^{*} \mathrm{p}<0.001,+\mathrm{p}<0.005, \ddagger \mathrm{p}<0.05$.

For each subject values of both sides were considered, unless cortical responses were absent and CCT undeterminable (see Results). Latency and CCT ranges are reported between brackets. evoked MAPs contralaterally in the biceps and thenar muscles and bilaterally in the tibialis anterior muscle (fig 1, right). Similar responses were obtained bilaterally and with a shorter latency after stimulation of the cervical or lumbar region (fig 1 , left).

The mean latency of MAPs evoked by cortical and spinal stimulation and the mean CCTs are shown in table 1 . The mean duration of MAPs was 24.9, SD $4.2 \mathrm{~ms}$ for biceps, $24 \cdot 2$, SD $4.8 \mathrm{~ms}$ for thenar, $28 \cdot 8$, SD $5.1 \mathrm{~ms}$ for tibialis anterior on cortical stimulation and 22.8 , SD $3.5 \mathrm{~ms}$ for biceps, 17.6 , SD $4.3 \mathrm{~ms}$ for thenar, 24.2 , SD 4.6 for tibialis anterior on spinal stimulation. The mean amplitude of MAPs was 0.99 , SD $0.61 \mathrm{mV}$ for biceps, 1.99 , SD $1.27 \mathrm{mV}$ for thenar, 1.34 , SD $0.81 \mathrm{mV}$ for tibialis anterior on cortical stimulation and 2.99 , SD $2.02 \mathrm{mV}$ for biceps, 6.71 , SD $5.41 \mathrm{mV}$ for thenar, 2.44, SD $1.61 \mathrm{mV}$ for tibialis anterior on spinal stimulation.

\section{Patients}

(1) Myelopathy alone The mean latency of cortical MAPs and the mean CCTs were significantly increased as compared with control subjects (see table 1), while the mean latency of MAPs evoked by spinal stimulation was not different from normals and in no case did the latency of cervical MAPs for either biceps or thenar muscle exceed the upper confidence limits of control population. Central motor conduction abnor- $\frac{\pi}{\square}$ malities were observed bilaterally in eight subjects (for both thenar and biceps in three cases, only for thenar in five) and unilaterally in the thenar muscle of one subject (see table 2). Responses evoked in the tibialis anterior by cortical stimulation were either delayed ob absent in 10 out of 11 patients (fig 2) (see table 2). Abnormalities of the central conduction of motor impulses for at least one muscle were observed in 11 out of 12 patients $(91.6 \%)$ of this group. The mean duration and amplitude of MAPs evoked by cortical or spinal stimulation were not different from those of normal controls.

Table 2 Incidence of abnormalities of motor responses evoked by direct cortical and spinal stimulation

\begin{tabular}{lrll}
\hline & \multicolumn{3}{c}{$\begin{array}{l}\text { Myelopathy+ } \\
\text { radiculopathy }\end{array}$} \\
& Mydiculopathy \\
\hline Biceps & & & \\
Absent cortical MAP & $1 / 24$ & $0 / 24$ & $0 / 12$ \\
Delayed cortical MAP & $5 / 24$ & $4 / 24$ & $1 / 12$ \\
Increased CCT & $5 / 24$ & $6 / 24$ & $0 / 12$ \\
Delayed cervical MAP & $0 / 24$ & $2 / 24$ & $1 / 12$ \\
Thenar & & & \\
Absent cortical MAP & $3 / 24$ & $1 / 24$ & $0 / 12$ \\
Delayed cortical MAP & $9 / 24$ & $18 / 24$ & $3 / 12$ \\
Increased CCT & $14 / 24$ & $20 / 24$ & $0 / 12$ \\
Delayed cervical MAP & $0 / 24$ & $8 / 24$ & $3 / 12$ \\
Tibialis $A$. & & & \\
Absent cortical MAP & $9 / 22$ & $6 / 18$ & \\
Delayed cortical MAP & $10 / 22$ & $9 / 18$ & \\
Increased CCT & $11 / 22$ & $9 / 18$ & \\
\hline
\end{tabular}




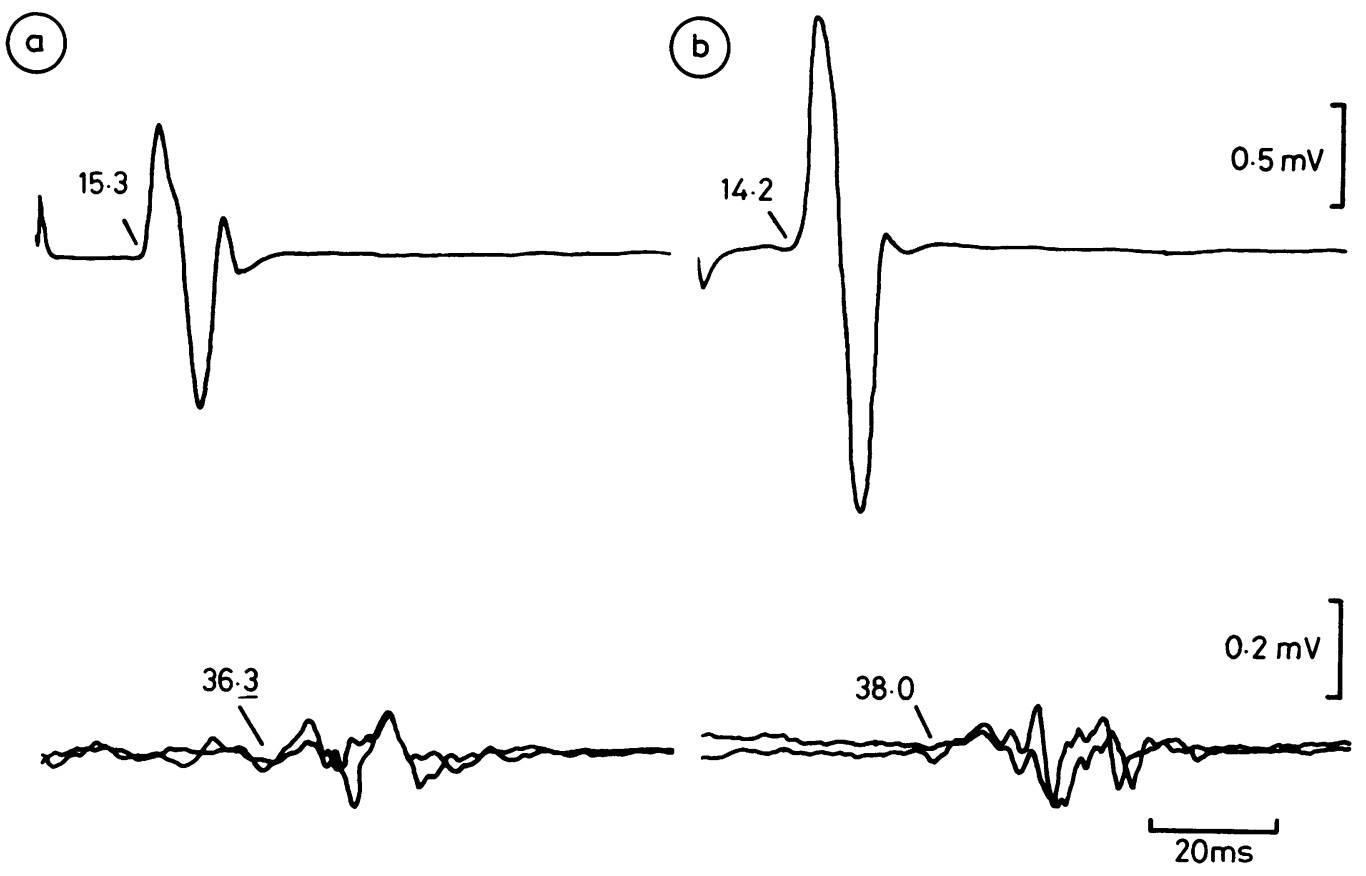

Fig 2 MAPs evoked by spinal (upper traces) and cortical (lower traces) electrical stimulation in the right (a) and left (b) tibialis anterior muscle of a patient with myelopathy due to cervical spondylosis. MAPs evoked by direct cortical stimulation are evidently reduced in amplitude and delayed in latency. In this and in the following figures, two samples upon cortical stimulation have been superimposed to show the reproducibility.

No abnormalities of conventional EMG recordings, median nerve MCV, F-wave and cervical SEP (N13) latency were observed. Increased latency of cortical SEPs was observed in two cases upon median nerve stimulation and in five out of 11 cases upon posterior tibial nerve stimulation. On the whole, SEP changes upon stimulation of either median or posterior tibial nerve were present in six subjects, all of them with impaired central motor conduction.

(2) Combined myelopathy and radiculopathy The mean latency of cortical MAPs and the mean CCTs were significantly increased, as well as the mean latency of cervical MAPs for biceps and thenar muscles (see table 1). Central abnormalities were observed bilaterally in eight subjects (for both thenar and biceps in two cases, only for thenar in six), while in two subjects they were observed unilaterally in the biceps and bilaterally in the thenar and in one subject unilaterally in the thenar (see table 2) (fig 3).

Responses evoked in the tibialis anterior muscle by cortical stimulation were either delayed or absent in eight out of nine patients (bilaterally in seven cases and unilaterally in one) (see table 2). The central con- duction of motor impulses was abnormal for at least one muscle in all the subjects $(100 \%)$ of this group.

The latency of the cervical MAPs was increased in five cases (two unilaterally) for the thenar and in two cases (unilaterally) for the biceps muscle. Latency abnormalities of cervical MAPs for at least one muscle could be observed in five subjects.

No change of the mean duration of either cortical or spinal MAPs was observed, while the mean amplitude of the thenar MAP on cortical stimulation was significantly reduced $(0.60, \mathrm{SD} 0.44 \mathrm{mV}, \mathrm{p}<0.001)$.

Evidence of denervation in at least one muscle was shown by conventional EMG studies in 10 patients (in the thenar in nine cases and in the biceps in six). Two patients showed a prolonged F-wave latency, while median nerve MCV was normal in all subjects. Increased latency of the cervical component (N13) of SEP to median nerve stimulation was observed in three cases, one of them showing also delayed cervical MAPs. Latency abnormalities of cortical SEPs were present in two subjects (with normal N13 latency) upon median nerve stimulation and in three out of nine patients upon posterior tibial nerve stimulation. 


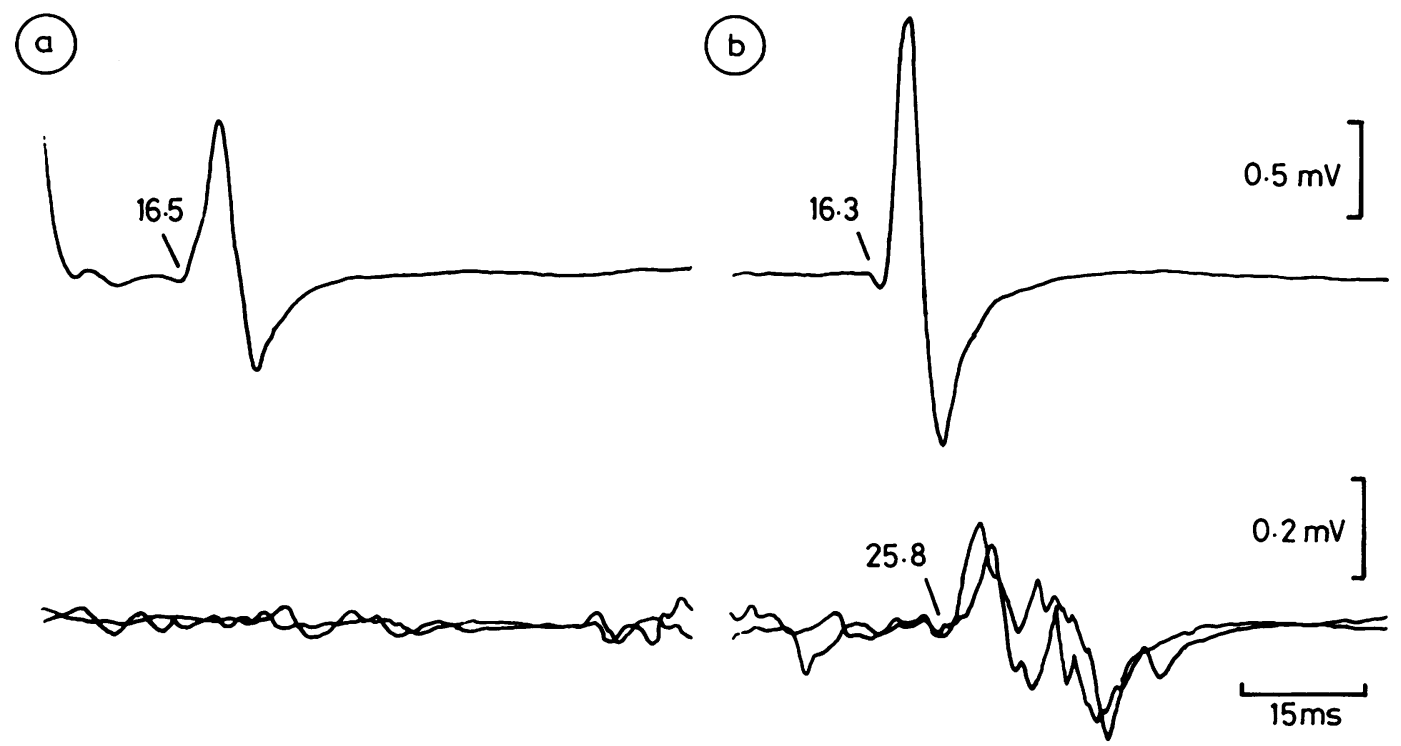

Fig 3 MAPs evoked by spinal (upper traces) and cortical (lower traces) electrical stimulation in the right (a) and left (b) thenar muscles of a patient with combined myelopathy and radiculopathy due to cervical spondylosis. The latency of cervical MAPs is increased bilaterally, while upon cortical stimulation MAPs are absent in the right and delayed in the left thenar muscles.

SEP abnormalities were paralleled by changes in motor conduction in all subjects but one who showed abnormalities of motor conduction at the lower limbs and of sensory conduction at the upper limbs.

(3) Radiculopathy alone All patients of this group showed clinical evidence of a unilateral sensorimotor radicular involvement, with EMG signs of denervation (in the thenar in five cases, in the biceps in two). Median nerve MCV and SEPs to median nerve stimulation were normal, while F-wave latency was increased in one patient. In three patients the latency of both cortical and cervical MAPs for the thenar muscle of the affected side exceeded the upper confidence limits, while the CCT was normal (fig 4).

\section{Discussion}

Muscle action potentials following electrical stimulation of the scalp (over the motor cortex) and of the cervical vertebral region are supposed to depend on direct activation of the corticospinal neurons ${ }^{12}$ and of the spinal ventral roots (at their exit foramina from the spinal canal $)^{15}$ respectively. Therefore, the CCT value can be regarded as a satisfactory approximation to the actual corticospinal conduction time. We have found abnormalities of central motor conduction for at least one muscle in all but one of the patients with spondylotic myelopathy, thus confirming the preliminary observations of Thompson et al. ${ }^{16}$ Such abnormalities were mainly represented by absence of responses to maximal cortical stimulation or by increase of cortical MAP latency and CCT. They occurred more frequently in thenar than in biceps muscles, as previously observed by Thompson et al. ${ }^{17}$ However, we were not able to establish whether this outcome was directly related to the level of spinal spondylotic compression, as has been suggested. ${ }^{17}$ In fact, the same pattern of alteration can also be found in other forms of non-compressive myelopathy of different aetiology 6910 Duration and amplitude of MAPs seemed to be less reliable parameters, though in single cases EMG responses were small and/or of increased duration, as already reported. ${ }^{17}$

Mechanisms possibly responsible for either absent or delayed EMG responses to electrical stimulation of the motor cortex in diseases of the upper motor neuron have been recently analysed by Thompson et al. ${ }^{17}$ Inter alia they argued that (a) absence of a response does not necessarily imply a complete disruption of the corticospinal connections; (b) latency delays of a few milliseconds may depend on a failure of the complex series of events required to depolarise spinal motoneurons, rather than on slowing of central conduction. In particular, owing to the desynchronis- 


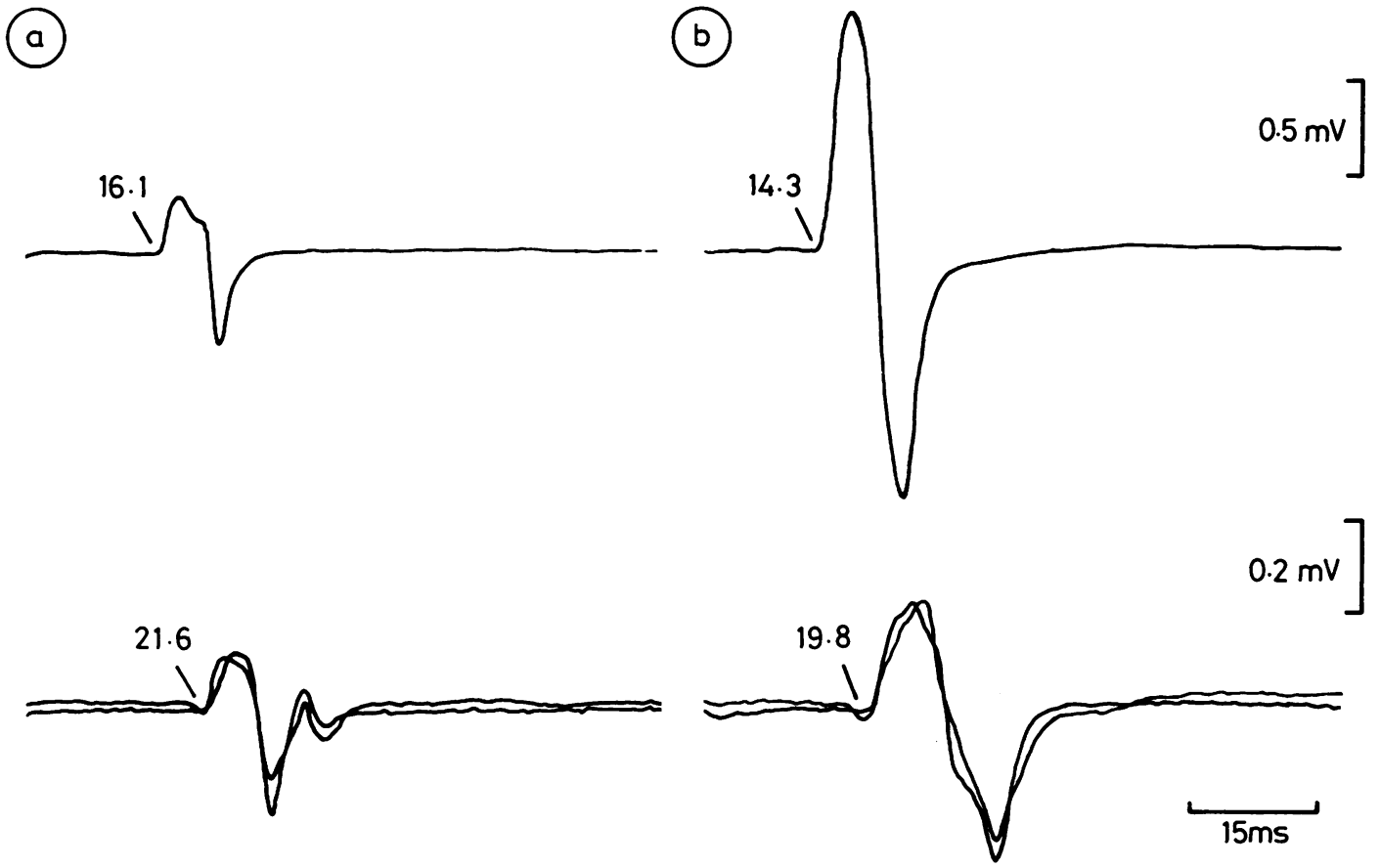

Fig 4 MAPs evoked by spinal (upper traces) and cortical (lower traces) stimulation in the right (a) and left (b) thenar muscles of a patient with right motor radiculopathy due to cervical spondylosis. Both cervical and cortical MAPs of the right thenar are reduced in amplitude and delayed in latency, but no difference of the CCT $(5.5 \mathrm{~ms})$ can be observed between the two sides.

ation of descending impulses "... temporal summation of successive EPSPs may be necessary to raise motoneurons to their firing threshold", ${ }^{12}$ since the first EPSPs following repetitive firing of pyramidal tract cells ${ }^{12} 18$ may be insufficient to discharge spinal motoneurons. Therefore, the pathophysiologic implications of both delayed and absent MAPs must be evaluated with caution also in spondylotic myelopathy.

MAP abnormalities were more severe at the lower than at the upper limbs, the absence of response occurring more frequently in the tibialis anterior than in either thenar or biceps muscles, possibly due to the different chronological dispersion of the respective corticospinal volleys. This is apparently in keeping with the higher incidence of SEP abnormalities upon posterior tibial than upon median nerve stimulation. ${ }^{1}$ In any case, changes in central motor conduction occurred more often than SEP abnormalities as previously observed by Thompson et al. ${ }^{16}$ This finding is consistent with the prevalent involvement of anterolateral quadrants of the spinal cord in cervical spondylosis ${ }^{319}$ and suggests that direct stimulation of motor tracts should be combined with SEP recordings when a complete functional evaluation of the spinal cord pathways is needed.

All patients with myelopathy (but one) showed both clinical involvement of the corticospinal tracts and central motor conduction abnormalities, but the electrophysiological changes were not necessarily proportional to the motor impairment degree.

Direct stimulation of the cervical region showed abnormalities of peripheral motor conduction in more than $40 \%$ of patients with clinical signs of radiculopathy. Similar changes, previously reported in patients with motor neuron disease ${ }^{10}$ or with acute and chronic demyelinating neuropathy, ${ }^{20}$ are likely to reflect the ventral root involvement since MCV was consistently normal. Moreover, cervical stimulation proved to be superior to the measurement of F-wave latency for studying conduction in the most proximal segments of the peripheral motor system. In this regard it may be relevant that recurrent discharges occur in a small fraction (approximately $1 \%$ ) of antidromically activated motoneurons ${ }^{21}$ and that their latencies are markedly variable, owing to activation of different populations of motoneurons by successive stimuli. ${ }^{22}$ Thus it is conceivable that the F-shortest 
latency can be biased in favour of the less affected motor fibres. We feel, therefore, that MAPs following spinal stimulation can be more representative than the F-wave of the actual ventral root damage. Summing up, recording MAPs following cortical and spinal stimulation in patients with myelo-radiculopathy due to cervical spondylosis is a suitable tool with which to detect motor conduction abnormalities both in the central descending pathways and in the peripheral radicular tracts.

Cortical and spinal stimulation were easily tolerated by our patients, who did not complain of any side effect. In addition, Cohen and Hallett ${ }^{23}$ were not able to demonstrate electroencephalographic evidence for short term epileptogenic effects of cortical stimulation.

We conclude that direct electrical stimulation of the motor pathways represents a further progress in the functional assessment of the neural damage in cervical spondylo:is possibly also with respect to longitudinal and/or post-surgical evaluation, as shown by some preliminary observations in patients of the present series.

\section{References}

$1 \mathrm{Yu} \mathrm{YL,} \mathrm{Jones} \mathrm{SJ.} \mathrm{Somatosensory} \mathrm{evoked} \mathrm{potentials} \mathrm{in} \mathrm{cervical}$ spondylosis: correlation of median, ulnar and posterior tibial nerve responses with clinical and radiological findings. Brain 1985;108:273-300.

2 Clarke E, Robinson PK. Cervical myelopathy: a complication of cervical spondylosis. Brain 1956;79:483-510.

3 Garfield J. Neurological manifestations of vertebral column disorders. In: Asbury AK, McKhann GM, McDonald WI, eds. Diseases of the Nervous System, vol. 2. Philadelphia: Saunders Co., 1986:1510-5.

4 Merton PA, Morton HB. Stimulation of the cerebral cortex in the intact human subjects. Nature 1980;285:227.

5 Merton PA, Morton HB, Hill DK, Marsden CD. Scope of a technique for electrical stimulation of human brain, spinal cord, and muscle. Lancet 1982;2:597-600.

6 Cowan JMA, Rothwell JC, Dick JPR, Day BL, Thompson PD, Marsden CD. Abnormalities in the central motor pathways in multiple sclerosis. Lancet 1984;2:304-7.

7 Mills KR, Murray NMF. Corticospinal tract conduction time in multiple sclerosis. Ann Neurol 1985;18:601-5.

8 Thompson PD, Dick JPR, Day BL, Rothwell JC, Berardelli A,
Kachi T, Marsden CD. Electrophysiology of the corticomotoneurone pathways in patients with movement disorders. Movement Disorders 1986;1:113-7.

9 Ingram DA, Swash M. Central motor conduction is abnormal in motor neuron disease. J Neurol Neurosurg Psychiatry 1987;50:159-66.

10 Berardelli A, Inghilleri M, Formisano R, Accornero N, Manfredi $M$. Stimulation of motor tracts in motor neuron disease. $J$ Neurol Neurosurg Psychiatry 1987;50:732-7.

11 Berardelli A, Inghilleri M, Manfredi M, Zamponi A, Cecconi V, Dolce G. Cortical and cervical stimulation after hemispheric infarction. J Neurol Neurosurg Psychiatry 1987;50:861-5.

12 Day BL, Thompson PD, Dick JP, Nakashima K, Marsden CD. Different sites of action of electrical and magnetic stimulation of the human brain. Neurosci Lett 1987;75:101-6.

13 Berardelli A, Cowan JMA, Day BL, Dick JP, Rothwell JC. The site of facilitation of the response to cortical stimulation during voluntary contraction in man. J Physiol (Lond) 1985;360: $52 \mathrm{P}$.

14 Abbruzzese G, Cocito L, Ratto S, Abbruzzese M, Leandri M, Favale E. A reassessment of sensory evoked potential parameters in multiple sclerosis: a discriminant analysis approach. J Neurol Neurosurg Psychiatry 1981;44:133-9.

15 Mills KR, Murray NMF. Electrical stimulation over the human vertebral column: which neural elements are excited? Electroencephalogr Clin Neurophysiol 1986;63:582-9.

16 Thompson PD, Dick JPR, Asselman P, et al. Examination of motor function in lesions of the spinal cord by stimulation of the motor cortex. Ann Neurol 1987;21:389-96.

17 Thompson PD, Day BL, Rothwell JC, Dick JPR, Cowan JMA, Asselman P, Griffin GB, Sheehy MP, Marsden CD. The interpretation of electromyographic responses to electrical stimulation of the motor cortex in diseases of the upper motor neurone. J Neurol Sci 1987;80:91-110.

18 Boyd SG, Rothwell JC, Cowan JMA, Webb PJ, Morley T, Asselman P, Marsden CD. A method of monitoring function in corticospinal pathway during scoliosis surgery with a note on motor conduction velocities. J Neurol Neurosurg Psychiatry 1986;49:251-7.

19 Yu YL, Du Boulay GH, Stevens JM, Kendall BE. Computerassisted myelography in cervical spondylotic myelopathy and radiculopathy. Clinical correlations and pathogenetic mechanisms. Brain 1986;109:259-78.

20 Mills KR, 1. .urray NMF. Proximal slowing and conduction block in acute and chronic demyelinating neuropathy. J Neurol Neurosurg Psychiatry 1986;49:476.

21 Eisen A, Odusote K. Amplitude of the F-wave: a potential means of documenting spasticity. Neurology 1979;29:1306-9.

22 Stalberg E, Trontelj JV. Single Fibre F'ectromyography. Old Woking, Surrey: The Mirvalle Press Limited, 1979:151-68.

23 Cohen LG, Hallett M. Cortic.d stimulation do not cause shortterm changes in the electroencephalogram. Ann Neurol 1987;21:512-3. 